\title{
Numerical Computation and Analysis of Heavy Medium Cyclone Turbulence Flow Field
}

\author{
XIA Yuming \\ The Internet of Things Technology Application Institute of \\ China Aerospace Science and Technology Corporation \\ Beijing, China \\ E-mail: xymen@sina.com
}

\begin{abstract}
The theory, model and algorithm of three products heavy medium cyclone flow field were researched, and the heavy medium cyclone flow field was simulated. Through the researches, the numerical discrete algorithm of heavy medium cyclone flow field was deduced, the calculation algorithms of heavy medium cyclone flow field were given, the flow trace in three products heavy medium cyclone, and the separation rules and flow field characteristics of three products heavy medium cyclone were obtained.
\end{abstract}

Keywords- heavy medium cyclone; turbulence flow field; numerical computation;

\section{INTRODUCTION}

Research the heavy medium cyclone flow field, establish the theoretical model of heavy medium cyclone flow field, study the algorithm of heavy medium cyclone flow field, simulate the heavy medium cyclone flow field, and obtain the separation rules and flow field characteristics of heavy medium cyclone [1-5], can provide scientific basis to the separation and theoretical research of heavy medium cyclone [6-10]. Utilize the research results in manufacture and technology applications can further improve the coal resources separation efficiency and coal products quality, and can increase the utilization of coal resources, thus, effectively increase the energy utilization, protect the environment, save the resources, and it is helpful to the sustainable development of social and economic life.

In this paper, the Reynolds stress transport equation of three products heavy medium cyclone flow field, the numerical discrete algorithm and computation process of heavy medium cyclone flow field were researched, and by numerical simulating the 3NZX1200-850 pressured feed three products heavy medium cyclone, the flow trace in three products heavy medium cyclone, and the separation rules and flow field characteristics of three products heavy medium cyclone were obtained.

\section{STRUCTURE AND PROCESS PARAMETERS}

3NZX1200-850 pressured feed three products heavy medium cyclone was selected for simulating, the side view of 3NZX1200-850 pressured feed three products heavy medium cyclone was shown in Fig.1, and the structure and process parameters of 3NZX1200-850 pressured feed three products heavy medium cyclone was shown in Table 1.

\author{
XU Zhiqiang, TU Yanan \\ School of Chemical and Environmental Engineering \\ China University of Mining and Technology \\ Beijing, China \\ E-mail: hmctf@126.com
}

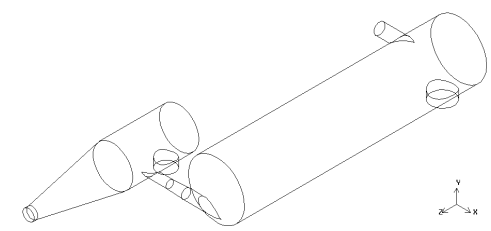

Figure 1. Side view of 3NZX1200-850 pressured feed three products heavy medium cyclone

TABLE I. STRUCTURE AND PROCESS PARAMETERS OF 3NZX1200-850 PRESSURED FEED THREE PRODUCTS HEAVY MEDIUM CYCLONE

\begin{tabular}{|c|c|c|c|}
\hline Parameters & Value & Parameters & Value \\
\hline one-stage cylinder diameter $(\mathrm{mm})$ & 1200 & feeding size $(\mathrm{mm})$ & $0-80$ \\
\hline two-stage cylinder diameter $(\mathrm{mm})$ & 850 & $\begin{array}{c}\text { operating } \\
\text { pressure }(\mathrm{MPa})\end{array}$ & $0.18-0.30$ \\
\hline feeding inlet diameter $(\mathrm{mm})$ & 240 & circulation $\left(\mathrm{m}^{3} \cdot \mathrm{h}^{-1}\right)$ & $800-1200$ \\
\hline $\begin{array}{c}\text { one-stage overflow outlet } \\
\text { diameter }(\mathrm{mm})\end{array}$ & 490 & $\begin{array}{c}\text { handling capacity } \\
\left(\mathrm{t} \cdot \mathrm{h}^{-1}\right)\end{array}$ & $250-350$ \\
\hline $\begin{array}{c}\text { two-stage overflow outlet } \\
\text { diameter }(\mathrm{mm})\end{array}$ & 380 & $\begin{array}{c}\text { installation } \\
\text { angular }\left({ }^{\circ}\right)\end{array}$ & 10 \\
\hline $\begin{array}{c}\text { two-stage underflow outlet } \\
\text { diameter }(\mathrm{mm})\end{array}$ & 240 & & \\
\hline \multicolumn{2}{|r|}{}
\end{tabular}

\section{FLOW FIELD COMPUTATION ALGORITHM PRINCIPLE}

The Reynolds stress transport equation of heavy medium cyclone flow field is

$$
\begin{aligned}
\frac{\partial}{\partial t}\left(\rho\left\langle u_{i}^{\prime} u_{j}^{\prime}\right\rangle\right) & +\frac{\partial}{\partial x_{k}}\left(\rho u_{k}\left\langle u_{i}^{\prime} u_{j}^{\prime}\right\rangle\right)=-\frac{\partial}{\partial x_{k}}\left[\rho\left\langle u_{i}^{\prime} u_{j}^{\prime} u_{k}^{\prime}\right\rangle+\left\langle p\left(\delta_{k j} u_{i}^{\prime}+\delta_{i k} u_{j}^{\prime}\right\rangle\right)\right] \\
& +\frac{\partial}{\partial x_{k}}\left[\eta \frac{\partial}{\partial x_{k}}\left\langle u_{i}^{\prime} u_{j}^{\prime}\right\rangle\right]-\rho \beta\left(g_{i}\left\langle u_{j}^{\prime} \theta\right\rangle+g_{j}\left\langle u_{i}^{\prime} \theta\right\rangle\right) \\
& -\rho\left(\left\langle u_{i}^{\prime} u_{k}^{\prime}\right\rangle \frac{\partial u_{j}}{\partial x_{k}}+\left\langle u_{j}^{\prime} u_{k}^{\prime}\right\rangle \frac{\partial u_{i}}{\partial x_{k}}\right) \\
& +\left\langle p\left(\frac{\partial u_{i}^{\prime}}{\partial x_{j}}+\frac{\partial u_{j}^{\prime}}{\partial x_{i}}\right)\right\rangle-2 \eta\left\langle\frac{\partial u_{i}^{\prime}}{\partial x_{k}} \frac{\partial u_{j}^{\prime}}{\partial x_{k}}\right\rangle \\
& -2 \rho \Phi_{k}\left(\left\langle u_{j}^{\prime} u_{m}^{\prime}\right\rangle \varepsilon_{i k m}+\left\langle u_{i}^{\prime} u_{m}^{\prime}\right\rangle \varepsilon_{j k m}\right)+S_{u s e r}
\end{aligned}
$$

Where $\frac{\partial}{\partial t}\left(\rho\left\langle u_{i}^{\prime} u_{j}^{\prime}\right\rangle\right)$ is Reynolds stress local time derivative of cyclone flow field, mark $L_{i j}, \frac{\partial}{\partial x_{k}}\left(\rho u_{k}\left\langle u_{i}^{\prime} u_{j}^{\prime}\right\rangle\right)$ is Reynolds stress convection item of cyclone flow field, mark $\Omega_{i j}$, 
$-\frac{\partial}{\partial x_{k}}\left[\rho\left\langle u_{i}^{\prime} u_{j}^{\prime} u_{k}^{\prime}\right\rangle+\left\langle p\left(\delta_{k j} u_{i}^{\prime}+\delta_{i k} u_{j}^{\prime}\right)\right\rangle\right]$ is Reynolds stress turbulence diffusion item of cyclone flow field, mark $D_{T, i j}$, $\frac{\partial}{\partial x_{k}}\left[\eta \frac{\partial}{\partial x_{k}}\left(\left\langle u_{i}^{\prime} u_{j}^{\prime}\right\rangle\right)\right]$ is Reynolds stress molecular diffusion item of cyclone flow field, mark $D_{M, i j},-\rho \beta\left(g_{i}\left\langle u_{j}^{\prime} \theta\right\rangle+g_{j}\left\langle u_{i}^{\prime} \theta\right\rangle\right)$ is Reynolds stress buoyancy item of cyclone flow field, mark $B_{i j}$, $-\rho\left(\left\langle u_{i}^{\prime} u_{k}^{\prime}\right\rangle \frac{\partial u_{j}}{\partial x_{k}}+\left\langle u_{j}^{\prime} u_{k}^{\prime}\right\rangle \frac{\partial u_{i}}{\partial x_{k}}\right)$ is Reynolds stress item of cyclone flow field, mark $P_{i j},\left\langle p\left(\frac{\partial u_{i}^{\prime}}{\partial x_{j}}+\frac{\partial u_{j}^{\prime}}{\partial x_{i}}\right)\right\rangle$ is Reynolds stress pressure strain item of cyclone flow field, mark $\varphi_{i j},-2 \eta\left\langle\frac{\partial u_{i}^{\prime}}{\partial x_{k}} \frac{\partial u_{j}^{\prime}}{\partial x_{k}}\right\rangle$ is Reynolds stress dissipation item of cyclone flow field, mark $\mathcal{E}_{i j}$, $-2 \rho \Phi_{k}\left(\left\langle u_{j}^{\prime} u_{m}^{\prime}\right\rangle \mathcal{E}_{i k m}+\left\langle u_{i}^{\prime} u_{m}^{\prime}\right\rangle \mathcal{E}_{j k m}\right)$ is Reynolds stress system rotary item of cyclone flow field, mark $R_{i j}, S_{u s e r}$ is Reynolds stress custom source item of cyclone flow field.

Set $\Omega$ is bounded domain on a vertical axial flow field cross-section $x-y$ in the cyclone flow field, $\Gamma$ is wall boundary curve, along the direction of $x$ axis and $y$ axis flow field take the step $\Delta x$ and $\Delta y$, make $\Delta x=h, \Delta y=l$. Set two straight line parallel to the $x$ axis and $y$ axis flow field

$$
\begin{aligned}
& x=x_{i}=i \Delta x=i h, \quad i=0, \pm 1, \pm 2, \cdots \\
& y=y_{j}=j \Delta y=j l, \quad j=0, \pm 1, \pm 2, \cdots
\end{aligned}
$$

Set point of the two straight lines intersection $\left(x_{i}, y_{j}\right)$, here abbreviated mark as $(i, j)$. Set $\Omega_{h}$ as collection of cyclone flow field inside point, Fig. 2 shows the mesh of flow field region $\Omega$. Take any one region in the flow field, the region is set to a point of the flow field area, $A\left(x_{i}, y_{j}\right)$ is the inner point of region $\Omega_{h}$, four adjacent points of $A\left(x_{i}, y_{j}\right)$ is $C_{1}\left(x_{i+1}, y_{j}\right)$, $C_{2}\left(x_{i}, y_{j+1}\right), C_{3}\left(x_{i-1}, y_{j}\right), C_{4}\left(x_{i}, y_{j-1}\right), B_{i}$ is the midpoint of $A C_{i}$, $i=1,2,3,4$.

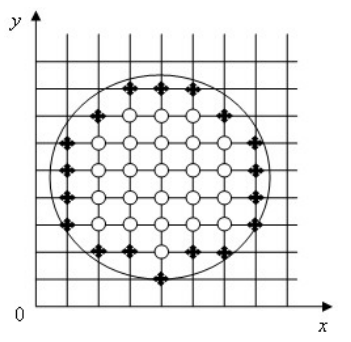

(a)

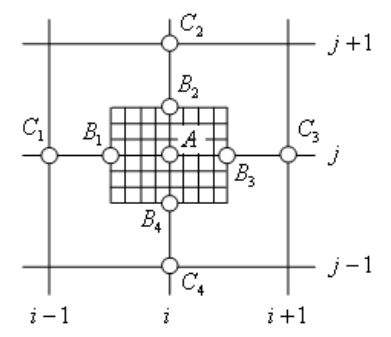

(b)
Figure 2. (a)Computational domain grid node partition of three products heavy medium cyclone, (b) Sketch map of numerical discrete flow field of three products heavy medium cyclone
Difference equation of the three products heavy medium cyclone flow field model is

$$
\begin{aligned}
& \rho\left\langle u_{i}^{\prime} u_{j}^{\prime}\right\rangle+\frac{1}{h}\left[\rho u_{k+\frac{1}{2}}\left\langle u_{i+\frac{1}{2}}^{\prime} u_{j+\frac{1}{2}}^{\prime}\right\rangle-\rho u_{k-\frac{1}{2}}\left\langle u_{i-\frac{1}{2}}^{\prime} u_{j-\frac{1}{2}}^{\prime}\right\rangle\right]
\end{aligned}
$$

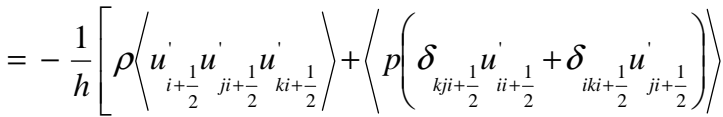

$$
\begin{aligned}
& \left.-\rho\left\langle u_{i-\frac{1}{2}}^{\prime} u_{j-\frac{1}{2}}^{\prime} u_{k-\frac{1}{2}}^{\prime}\right\rangle-\left\langle p\left(\delta_{k j-\frac{1}{2} u_{i-\frac{1}{2}}^{\prime}}+\delta_{i k-\frac{1}{2}} u_{j-\frac{1}{2}}^{\prime}\right)\right\rangle\right] \\
& +\frac{1}{h^{2}}\left[\eta\left(\left\langle u_{i+1}^{\prime} u_{j+1}^{\prime}\right\rangle-\left\langle u_{i}^{\prime} u_{j}^{\prime}\right\rangle\right)-\eta\left(\left\langle u_{i}^{\prime} u_{j}^{\prime}\right\rangle-\left\langle u_{i-1}^{\prime} u_{j-1}^{\prime}\right\rangle\right)\right] \\
& -\left[\rho \beta\left(g_{i}\left\langle u_{j}^{\prime} \theta\right\rangle+g_{j}\left\langle u_{i}^{\prime} \theta\right\rangle\right)\right] \\
& -\frac{1}{h}\left[\rho\left\langle u_{i}^{\prime} u_{k}^{\prime}\right\rangle\left(u_{j+\frac{1}{2}}-u_{j-\frac{1}{2}}\right)+\rho\left\langle u_{j}^{\prime} u_{k}^{\prime}\right\rangle\left(u_{i+\frac{1}{2}}-u_{i-\frac{1}{2}}\right)\right] \\
& +\left\langle\frac{p}{l}\left[u_{i+\frac{1}{2}}^{\prime}-u_{i-\frac{1}{2}}^{\prime}\right]+\frac{p}{h}\left[u_{j+\frac{1}{2}}^{\prime}-u_{j-\frac{1}{2}}^{\prime}\right]\right\rangle \\
& -\frac{2 \eta}{h l}\left[\left\langle\left(u_{i+\frac{1}{2}}^{\prime}-u_{i-\frac{1}{2}}^{\prime}\right)\left(u_{j+\frac{1}{2}}^{\prime}-u_{j-\frac{1}{2}}^{\prime}\right)\right\rangle\right] \\
& -2 \rho \Phi_{k}\left(\left\langle u_{j}^{\prime} u_{m}^{\prime}\right\rangle \varepsilon_{i k m}+\left\langle u_{i}^{\prime} u_{m}^{\prime}\right\rangle \varepsilon_{j k m}\right)+S_{u s e r}
\end{aligned}
$$

The above equation (2) is the numerical discrete format of three products heavy medium cyclone flow field model

Three products heavy medium cyclone flow field can be described by pressure-velocity coupling, step by step iterative computation process is needed for flow field computation, and it can be divided into:

(1) Introduce the pre-estimate pressure field into the momentum equations of three products heavy medium cyclone flow field, obtain the velocity field.

(2) Solve the pressure correction equation derived from the continuity equation of three products heavy medium cyclone flow field to obtain the corrected pressure equation.

(3) Do iterative computation of the new velocity and pressure field based on the corrected pressure equation. In the initial stage of the iterative computation process, assumed the initial estimated velocity and pressure fields firstly, and then compute the new velocity and pressure field constantly. The velocity and pressure fields will be convergence if the velocity field satisfies the continuity equation of the cyclone flow field and the solution is completed.

\section{FLOW TRACE IN THREE PRODUCTS HEAVY MEDIUM CYCLONE}

3NZX1200-850 pressured feed three products heavy medium cyclone was selected for the flow trace research in the cyclone, and the side, back and bottom view of flow trace in three products heavy medium cyclone were shown in Fig.3 and Fig.4. 


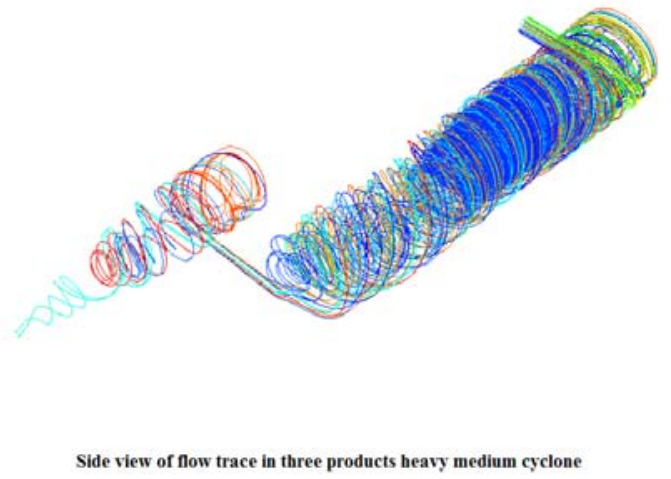

Figure 3. Side view of flow trace in three products heavy medium cyclone
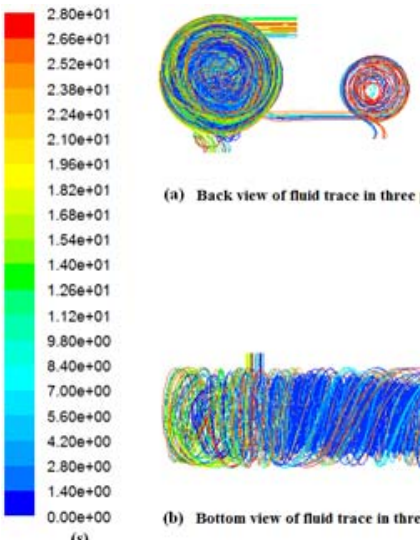

(a) Back view of nuid trace in three products heavy medium cyclone

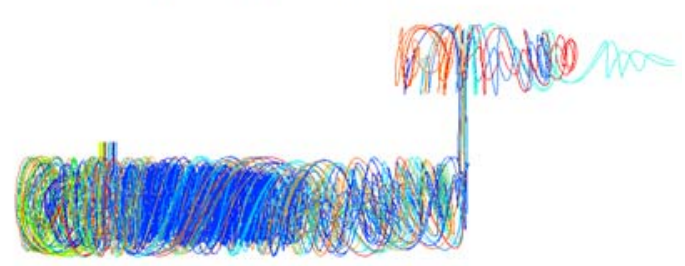

(b) Bottom view of nabd trace in three products heavy medium cyclone

Figure 4. Back view and bottom view of fluid trace in three products heavy medium cyclone

It is turbulence flow when the mixture flows into the three products heavy medium cyclone, according to research results, the movement property is complex and as shown in Fig.3 and Fig.4, it can be mainly described as:

1) The fluid that is near the wall of three products heavy medium cyclone does external swirl movement, a strong external swirl forms near the cylinder wall. The external swirl expands rapidly into the both one-stage overflow outlet direction and one-stage underflow outlet direction, part of the upward external swirl flows out the three products heavy medium cyclone through the overflow outlet when it flows through the one-stage overflow outlet, the other part of the upward external swirl generates downward internal swirl when it flows to the top wall of one-stage cylinder, and when the internal swirl flows through the one-stage overflow outlet, part of them flows out through one-stage overflow outlet, and the remaining part flows toward the bottom of one-stage cylinder.

2) When the mixture flows from the feeding inlet to the underflow outlet direction of one-stage cylinder, the external swirl is formed. Part of the mixture flows into the two-stage for separation through one-stage underflow outlet, and when the other part flows to the bottom of one-stage cylinder, for subjecting to the obstruction role of bottom cylinder wall and the accompanied role of strong external swirl, reverse internal swirl is formed inside the external swirl, and it rotationally flows toward the top of one-stage cylinder.
3) After part of the lighter density particles in the feeding flow into one-stage cylinder, for subjecting to the role of external swirl and internal swirl, the internal swirl happens before it reaches the bottom of one-stage cylinder.

4) The distribution of internal swirl mainly rotationally flows toward the top of one-stage cylinder. This internal swirl subjects to the feeding flow impact, when it flows near the tangent of feeding inlet and one-stage cylinder. The internal swirl near the tangent of feeding inlet and one-stage cylinder accelerated flows toward the one-stage overflow outlet, and experiences the flow behavior of process 1), for subjecting to the impact of feeding centrifugal swirl, while the tendency that flowing toward the top one-stage cylinder of internal swirl more away from the tangent of feeding inlet and one-stage cylinder is slow up, for subjecting to the impact of external swirl that flows toward the bottom one-stage cylinder, but it still flows toward the top one-stage cylinder overall, and it will experience the flow behavior of process 1 ).

5) Process 1)-4) are continuous with the feeding continuous, which makes the mixture accumulated in the middle-upper part is more than other position of one-stage cylinder, and the actual separation in one-stage cylinder mainly occurs within the described accumulated region.

6) The mixture of particles and heavy medium suspension at bottom one-stage cylinder flows into two-stage for separation through the one-two-stage connecting pipe. When the mixture flows to the tangent of connecting pipe and twostage cylinder, the centrifugal process occurs again. The mixture mainly flows toward both two-stage overflow outlet direction and two-stage underflow outlet direction after flowing into the two-stage cylinder, and then the external swirl and internal swirl are formed. Particles in the mixture flow out the corresponding overflow outlet and underflow outlet by the collective effect of the external swirl and internal swirl, thereby achieves separation.

7) The external swirl that forms during the mixture flowing toward the two-stage underflow outlet flows out trough the two-stage underflow outlet. The larger density particles mainly accumulate at the bottom of two-stage by the swirl effect of the one-stage cylinder, and then the particles flows out the twostage underflow outlet of three products heavy medium cyclone through the two-stage underflow outlet with heavy medium suspension.

8) The internal swirl forms before the lighter density particles reach the bottom of two-stage, for subjecting to the role of external swirl in cylinder and obstruction of two-stage cone wall, after the lighter density particles flow into the twostage cylinder.

9) The external swirl and internal swirl are reversed in the two-stage, and the internal swirl rotational flows toward the top of two-stage. The distribution of internal swirl mainly rotationally flows toward the top of two-stage cylinder with the center axis of $\mathrm{Z}$ axis. This internal swirl subjects to impact of the two-stage feeding flow when it flows near the tangent of two-stage feeding inlet and two-stage cylinder. The internal swirl near the tangent of two-stage feeding inlet and two-stage cylinder accelerated flows toward the two-stage overflow 
outlet, for subjecting to the impact of feeding centrifugal swirl, while the tendency that flowing toward the top of two-stage of internal swirl more away from the tangent of two-stage feeding inlet and two-stage cylinder is slow up, for subjecting to the impact of external swirl that flows toward the bottom of twostage, but it still flows toward the top of two-stage overall.

10) As shown in Fig.3 and Fig.4, the generation process of internal swirl in two-stage is different from the one-stage cylinder. Most of the internal swirl in the two-stage concentrated forms in the two-stage cylinder and middle-upper part of the cone, in addition, the mixture accumulated in the two-stage cylinder and middle-upper part of the cone is more than other position of the two-stage, and the actual separation in two-stage mainly occurs within the described accumulated region.

\section{CONCLUSIONS}

1) The flow trace in one-stage of three products heavy medium cyclone is intensive, and the upper flow trace is intensive than other parts in one-stage.

2) The main separation occurs in one-stage, addition, it can be seen, the centrifugal behavior immediately occurs immediately at tangent position of one-stage cylinder, when the particles mixed with heavy media suspension mixture goes into the feed port.

3) When the mixture goes into one-stage cylinder, it mainly flows toward to overflow outlet and underflow outlet direction of one-stage cylinder, and forms external swirl and internal swirl flow.
4) Particles in the mixture flow out the corresponding overflow outlet and underflow outlet by the collective effect of the external swirl and internal swirl, thereby achieves separation

\section{REFERENCES}

[1] XIA Yuming, WANG Weidong, and XU Zhiqiang,"Numerical computation of laminar flow pipeline transport axial flow field,” 2009 International Conference on Information Technology and Computer Science (ICITCS 2009), 2009, pp. 196-199.

[2] Xia Yuming and XU Zhiqiang, "Electromagnetic Flowmeter Measurement and Numerical Computation of Laminar Flow Transport Pipeline Flow Quantity,” 2009 Second International Symposium on Electronic Commerce and Security (ISECS 2009), 2009, pp. 169-173.

[3] Zhiqiang $\mathrm{Xu}$, Yuming Xia, "Numerical Simulation of Coal Water Mixture Pipeline Transport Axial Flow Field,” 2008 International Conference on Computer Science and Information Technology (ICCSIT 2008), 2008, pp. 243-246.

[4] XIA Yuming, TIAN Jinyun, XU Zhiqiang, WANG Weidong, "Computational error of laminar flow pipeline transport axial flow field,” 2009 International Conference on Computer Science and Information Technology (ICCSIT 2009), 2009, pp. 635-639.

[5] R. O. Fox. Computational Models for Turbulent Reacting Flows. Cambridge University Press, Cambridge, England, 2003

[6] W. Kraipech, A. Nowakowski, T. Dyakowski, et al. An investigation of the particle-fluid and particle-particle interactions on the flow within a hydrocyclone. Chem. Eng. J., 2005, 111: 189-197

[7] Jonas Bergstrom, Hannes Vomhoff. Experimental hydrocyclone flow field studies. Separation and Purification Technology, 2007, 53: 8-20

[8] Trong T. Bui. A Parallel, Finite-Volume Algorithm for Large-Eddy Simulation of Turbulent Flows. Technical Memorandum NASA/TM1999-206570, 1999

[9] H. Ibdir, H. Arastoopour. Modeling of multi-type particle flow using kinetic approach. AICHE Journal, 2005

[10] D. Ma, G. Ahmadi. A Thermodynamical Formulation for Dispersed Multiphase Turbulent Flows. Int. J. Multiphase Flow, 1990, 16: 323-351 